\title{
hacia la codificación de un centauro de los géneros \\ "El ensayo" como la práctica de escritura en artes
}
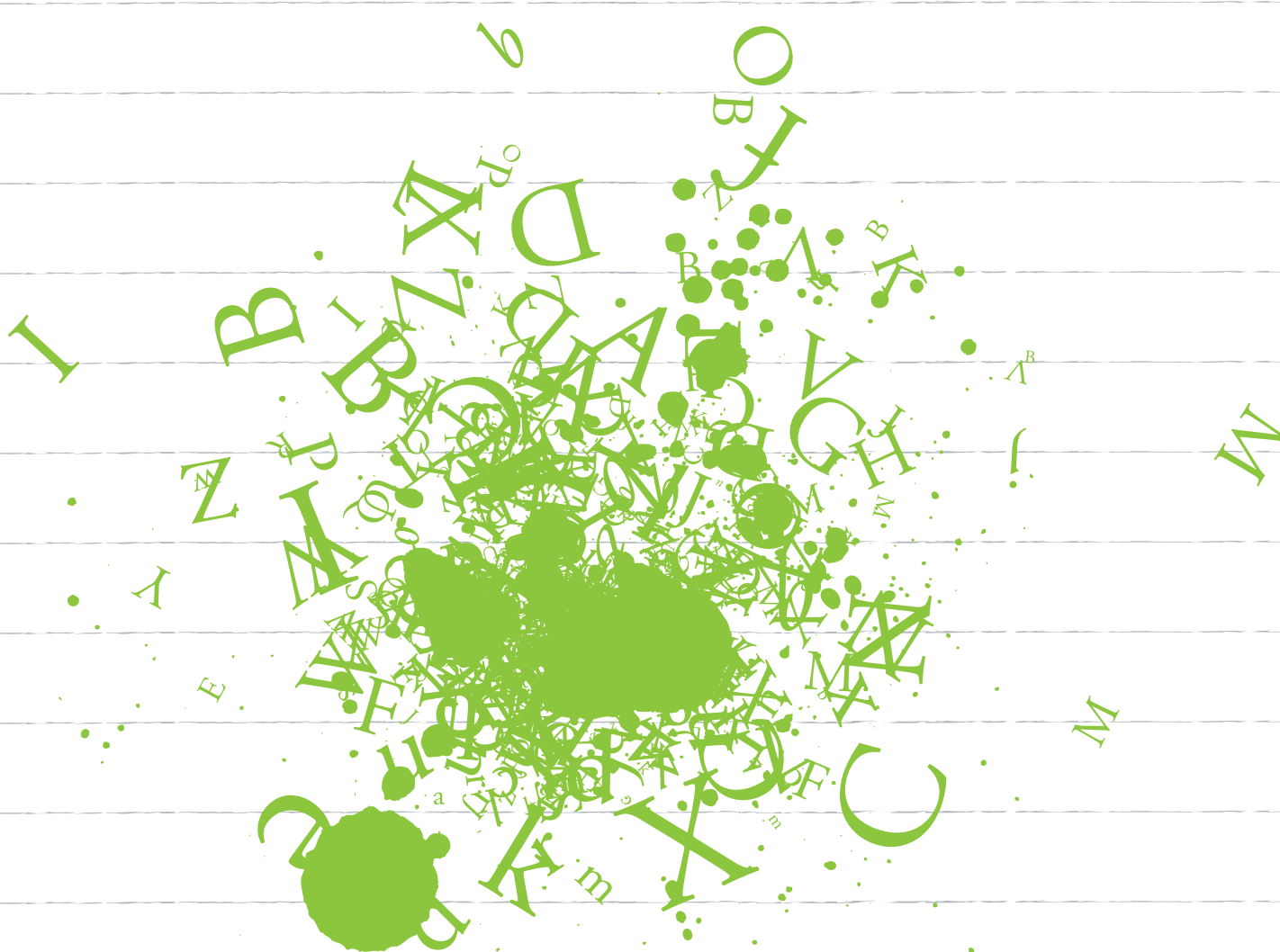

Ana María Gómez-Londoño

"Estetical Education: training of imagination for Epistemological performance" (Butler, 2010)1 
Ya no puedo decir que "pienso, luego existo" sino "creo lenguaje para existir". Este posicionamiento que exige la práctica artística contemporánea condiciona centralmente la concepción misma de Escritura, y las modalidades de relación textual que usa el artista para hacer existir "su proceso" en el lenguaje. De manera nodal, determina el lugar desde dónde se escribe la imagen. Por tal razón, el interés de este ensayo, gira en torno a las intervenciones "Traducciones y Traductores" y "Texturas y Textualidades", que hicieron parte del ciclo del Seminario Especial La escritura como práctica en la Maestría Artes Plásticas y Visuales de la Universidad Nacional de Colombia, y que me activan a formular una reflexión respecto a la práctica de escribir en Artes a partir de un genero textual: el ensayo. Éste, como género de escritura, es hibrido y plural, pues contiene y combina diferentes tipos de discursividades. Así mismo, su escritura exige una manera de operación intermedial entre la dimensión estética (artel y la dimensión epistémica (ciencia). En esta perspectiva, el Ensayo como el centauro de los géneros (Skirius, J., 1989), me permite establecer una modalidad textual de relación del artista con el texto escrito y me sirve como metáfora de la práctica artística contemporánea.

\title{
PALABRAS CLAVES
}

Escritura como tecnología de la palabra, la práctica de escribir en artes, modalidades de relación textual, ensayo, dimensión estética lartel y epistémica (ciencia).

\section{TOWARDS THE CODIFICATION OF A CENTAUR OF GENRES "THE ESSAY" AS A WRITING PRACTICE IN ARTS}

\begin{abstract}
I am not further able to say "I think therefore I am" but rather "I create language in order to exist". This reasoning, which has become a requirement of the exercise of contemporary art, determines the conception of writing and other manners of communication used by artists to make their "process" exist in language. The question arises: "from where is the image written". This essay inquires in the praxis of writing in the arts from a specific genre: the essay, and was inspired by the interventions "Translations and Tranlators" and "Textures and Textualities" from the seminar: La escritura como práctica, of the Master in Plastic and Visual Arts of Universidad Nacional de Colombia. The essay as a genre is hybrid and plural, as it combines different types of discourses. At the same time, its writing requires an intermedial operation between the esthetic dimension (art) and the epistemic dimension (science). In this manner, the Essay as the centaur of genres (Skirius, J., 1989), allows me to establish a manner of communication between the artist and its writing and serves as a metaphor of the exercise of contemporary art.
\end{abstract}

\section{KEYWORDS}

Writing as the technology of words, writing, arts, manners of communication, essay, esthetic (art) and epistemic dimension (science). 


\section{RUMO A UM CENTAURO DOS GÊNEROS "O ENSAIO", COMO A PRÁTICA DA ESCRITA EM ARTES}

\section{Resumo}

Não posso dizer mais que "eu penso, logo existo", senão "crio linguagem para existir." Este posicionamento que requer a prática artística contemporânea determina centralmente a própria concepção de Escritura, e as modalidades de relação textual que usa o artista para fazer existir "o seu processo" na Linguagem. De forma nodal, determina o lugar desde onde é escrita a imagem. Por esta razão, o interesse deste ensaio, ao redor às intervenções: "Traduções e Tradutores" e "Texturas e Textualidades", que fizeram parte do ciclo do Seminário Especial A escritura como prática na Mestria Artes Plásticas e Visuais da Universidade Nacional da Colômbia, ativa em mim a formulação de uma reflexão ao redor à prática de escrever em Artes partindo de um gênero textual: o ensaio. Este, como um gênero de escritura é híbrido e plural, pois contém e combina diferentes tipos de discursos. Da mesma forma, sua escritura exige uma forma de operação intermedial: entre a dimensão estética (arte) e a dimensão epistêmica (ciência). Nesta perspectiva, o ensaio como o centauro dos gêneros (Skirius, J., 2989), me permite estabelecer uma modalidade textual de relação do artista com o texto escrito e serve como metáfora da prática artística contemporânea.

\section{Palavras chave}

Escritura como tecnologia da palavra, a prática de escrever em artes, modalidades de relação textual, Ensaio, dimensão estética (arte) e epistêmica (ciência).

Si bien el reto que alberga el proceso de formación superior es el desarrollo de competencias "plurilingüísticas" -que algunos autores relacionan con la empatía tecnológica- potenciar el esfuerzo por comprender el registro mediático requiere de la sedimentación de un registro mediador: la escritura. Es aquí donde los actuales debates educativos y artísticos entran a hacer sus consideraciones: ¿informática sin escritura? (Mockus, 1996), para considerarlas finalmente como dos mediaciones que hacen parte de una "redistribución comunicativa continua y conjunta en la contemporaneidad" (Cassany, 1995; 2000). Por tal motivo, el problema central suscrito en la conferencia "Texturas y Textualidades" por el profesor Gilberto Bello para el seminario especial de la Maestría de Artes Plásticas y Visuales en la Universidad Nacional, circulaba en torno a las modalidades de relación textual, es decir, en torno a las adaptaciones que sufre la sensibilidad y la información en virtud de las exigencias e intenciones del texto, el escritor-artista y el contexto.

Desde esta perspectiva, las palabras se definen por sus usos y se denominan por divisiones de la praxis comunicativa que separó el ser del lenguaje (crf. Mass Comunication Research). Ello enmarca nuevamente la pregunta por el problema de la traducción que no refiere a la correspondencia -uno a uno- de los términos, pues "la tradution n'est ni une réception, ni une comunication, ni una reproduction d'un texte dans de une autre langue" (Derrida, 1971). El problema de la traducción, al mismo tiempo necesaria pero imposible, nos permite ubicar el lenguaje de una manera más cauta a la hora de decir que el arte es un lenguaje o que domina un lenguaje. Por tal motivo, para este escrito propongo ubicar una manera de operación intermedial que opera en el campo de la sensibilidad y el co- 
nocimiento: el ensayo. Sugiero alentar su consideración como un género escrito hibrido que señala la relación del artista con el texto escrito, y a su vez, se convierte en metáfora del proceso artístico. Para formular esta tesis debemos considerar que la escritura, como "herramienta imprescindible de la mente" (Vigotsky, 1995), restructura la conciencia (Ong, 1987) y -siguiendo la metáfora computacional- la formatea para sostener la manera como codificamos el mundo sensible.

El ingreso del sujeto al universo textual que su cultura le propone, en la oportunidad de verse enfrentado a textos de diversa naturaleza, enmarca una dificultad tanto cognoscitiva como semántica. Debido a que la escritura, como herramienta cognitiva es la responsable de estructurar la mente en un "pensamiento textualmente estructurado que hace hablar lo sensible en el lenguaje" (Wells, 1989). el escenario de aquello que llamamos escritura trae consigo la necesaria sensibilidad y planificación de lo escrito; la reflexión sobre la intención y la necesidad de asumir el proceso mismo (la dimensión metacognitival en el recurso de composición y regulación.

Sin embargo, en ocasiones, la concepción que se tiene de escritura mantiene una impresión muy tradicional. Se concibe como una invención puramente técnica, que permite pasar del registro audible al visual, convirtiendo el orden secuencial en un orden visual lineal. De esta manera, aprender a leer no sería más que aprender a asociar formas gráficas a unidades fónicas, y aprender a escribir, sinónimo de la grafía de las letras que están a disposición del hablante. En el campo de las artes creo que esta impresión tradicional de escritura ha servido como abono ideal para generar y reforzar el temor por su práctica, incrementando el estigma de la escritura creativa como "imposible y cosa de literatos" en consonancia con la frase contraria, de "la escritura como ladrillo' o adversa al proceso creativo" (Bustamente, 1993; 1999). Igualmente, la sobrevaloración del hecho escritural o la sensación de la escritura como forma artística elevada (la poesía), ha mediatizado el interés del artista, y a su vez, inmovilizado su atención y apertura, pues éste aminora el sentido pragmático y programático del quehacer escritural. Esta visión no sólo ha simplificado el problema sino que lo ha deformado. La escritura al contrario, está muy lejos de ser un mero recurso transcriptivo de la cadena hablada, pues ha sido la responsable del surgimiento del pensamiento -es la técnica de cómo pensamos ${ }^{6}$ y ha sido aquella la que le ha otorgado un nuevo estatuto a la existencia del hombre (Derrida 1971).

Al argumentar la dimensión plural del sujeto que es atravesado por diferentes tipos de discursividad (el jurídico-político, científico, narrativo-literario, mediáticol como lo hizo el Profesor Bello en la intervención "Texturas y Textualidades", ubicó el problema de la escritura en el campo de las modalidades de relación textual. Esta disposición enmarca la práctica escritural en la situación de tomar decisiones reflexivas con relación a la creación, planificación, y en torno a una aproximación significativa de lo escrito. Las diferentes modalidades planteadas atienden la resolución dialéctica entre el qué escribir y el cómo hacerlo en la fórmula de "decir el conocimiento”, así mismo, la reflexión sobre el conflicto entre las exigencias de la sensibilidad ly el pensamientol junto a las exigencias propias del texto; es decir, entre el "espacio sustantivo" (creencias, sensibilidad y conocimiento de quien escribel y el "espacio retórico" (exigencias textuales) en la función de "transformar el conocimiento". Este último objetivo, que fundamenta la escritura como tecnología de la palabra, es el lugar que comparten la dimensión epistémica y la dimensión estética.

Con la escritura se da paso a una manera especial de escribir el mundo que emprende el fondo de los signos-sistemas que disponemos o -siguiendo el discurso psicoanalítico- que "disponen de nosotros" (Lacan, 1971). Por un lado, se plantea la escritura como un desplazamiento espacial de exploraciones internas, donde el lenguaje vislumbra la potencia misma del lenguaje, apresado por el poema. Un espacio que en muchas ocasiones es inaprensible por la palabra. Este espacio es habitado por la imagen, haciendo al sujeto participar de una "alquimia de misterio" que reside en el primer asombro de la expresión. Por el otro lado, escribir y comunicar la experiencia, remite a un lenguaje inscrito en marcos comunicativos que participan de convenciones sociales y que le permiten hacer extensible lo que se pretende vislumbrar. En esta perspectiva, el ensayo como un género de escritura hibrida o centauro de los géneros, relaciona la autonomía de los signos escritos ${ }^{7}$ y la actividad del pen-

6 "Sin la escritura, el pensamiento no pensaría ni podría pensar como lo hace, no sólo cuando está ocupado en escribir, sino incluso cuando articula sus pensamientos de manera oral." (Ong, 81, 1987). 
samiento abstracto: es escritura que se construye en el diálogo entre las exploraciones internas de la subjetividad y la manera de organizarlas y formularlas.

En primera instancia, el ensayo nos permite hablar de una modalidad de escritura que exige articular tanto ideas (ciencia) como expresión y formas (arte). Es un género de naturaleza versátil por el elemento personal y el eje subjetivo que lo caracteriza, como dice Ortega y Gasset, "es una disertación científica sin prueba implícita".

En segunda instancia, debido a su carácter de experimentación, podemos decir, que el ensayo funciona como metáfora del proceso artístico, pues de esta "constelación sagitariana" (sensación/ idea-expresión) se desprende un tipo de escritura productiva que se diferencia de una escritura reproductiva (Vigotsky, 1993). Tal es la actividad que pretende el arte, y el quehacer del artista que busca la "transformación de conocimiento y la experiencia sensible". Igualmente sucede con la ciencia en su discurrir investigativo, pues va construyendo sentido en la turbulencia del lenguaje y reorganizando el caos. Todos los procesos que intervienen en el ensayo interactúan de una manera recursiva y no lineal. En el proceso, se tienen en cuenta los sentidos implicados en la selección y se organizan los mecanismos afectivos y cognitivos con el fin de enfrentarse a situaciones problema. Se ensaya y se escribe en relación con un problema. Este aspecto dispone al artista en un lugar de experimentación constante: el laboratorio.

Artista y científico entran a un espacio de escritura problemática que debe plantearse un modelo que atienda el proceso de arriesgarse como autores fundamentales del texto, a jugar con sus ideas y estilos, a reflexionar y partir de sus inquietudes (en un mismo intento por resolverlas). El ensayo como práctica de escritura opera como un Centauro: el arquero persigue un objetivo (sensaciones, ideas y conceptos) y el caballo, a la expresión sen-

discurso psicoanalítico refiere en torno a "la función de lo Escrito" (Lacan, 1972) pues acoge el tema desde el mismo lugar donde el lenguaje interroga su naturaleza: la relación significante-significado. En relación con el planteamiento clásico de la lingüística, el discurso analítico insiste en la autonomía de los signos escritos, enunciando que el significante nada tiene que ver con los oídos, sino con la lectura, la lectura de lo que se habla y escucha del significante, dando paso al sujeto del inconsciente que escribe. Este, quien

en su discurrir narrativo anuncia claramente una manera propia de enunciar la realidad, su realidad. Desde esta óptica, la correspondencia entre el significado y el significante desaparece en cuanto la realidad no se refleja en el lenguaje, pues es producto del lenguaje.

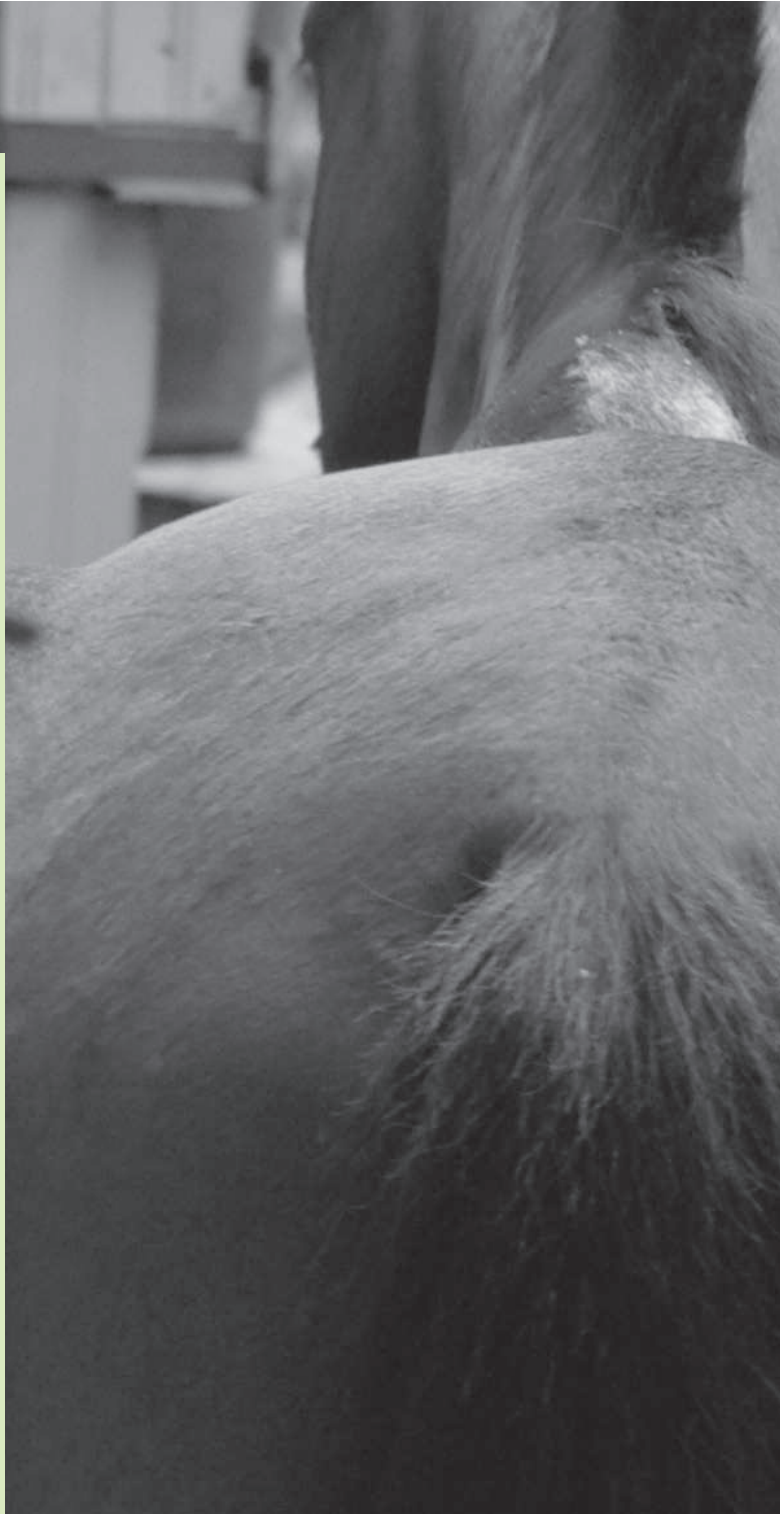

sible (arte). En este binomio ecuestre se encuentra la actividad artística y el proceso de escritura que señala el proceso de investigación-creación.

En el marco que define el ensayo como un centauro, en la articulación de la escritura que opera entre una afirmación de la subjetividad (arte) y la dimensión epistémica de ordenamiento formal de un concepto (investigación), se le exige al artista cambiar y combinar saberes, interpelar los propios conocimientos, haciendo que estos se renueven de manera constante e incesante.

Complementando los tipos discursivos que abordó el profesor Bello, considero que el Ensayo y su escritura propone la última escala de las modalidades de relación textual del sujeto -es el último eslabón de la escritura como proceso-. Es una forma textual muy desarrollada y exigente, pues como género híbrido contiene todas las otras formas de expresión escrita. Para demostrar esto, debemos considerar 


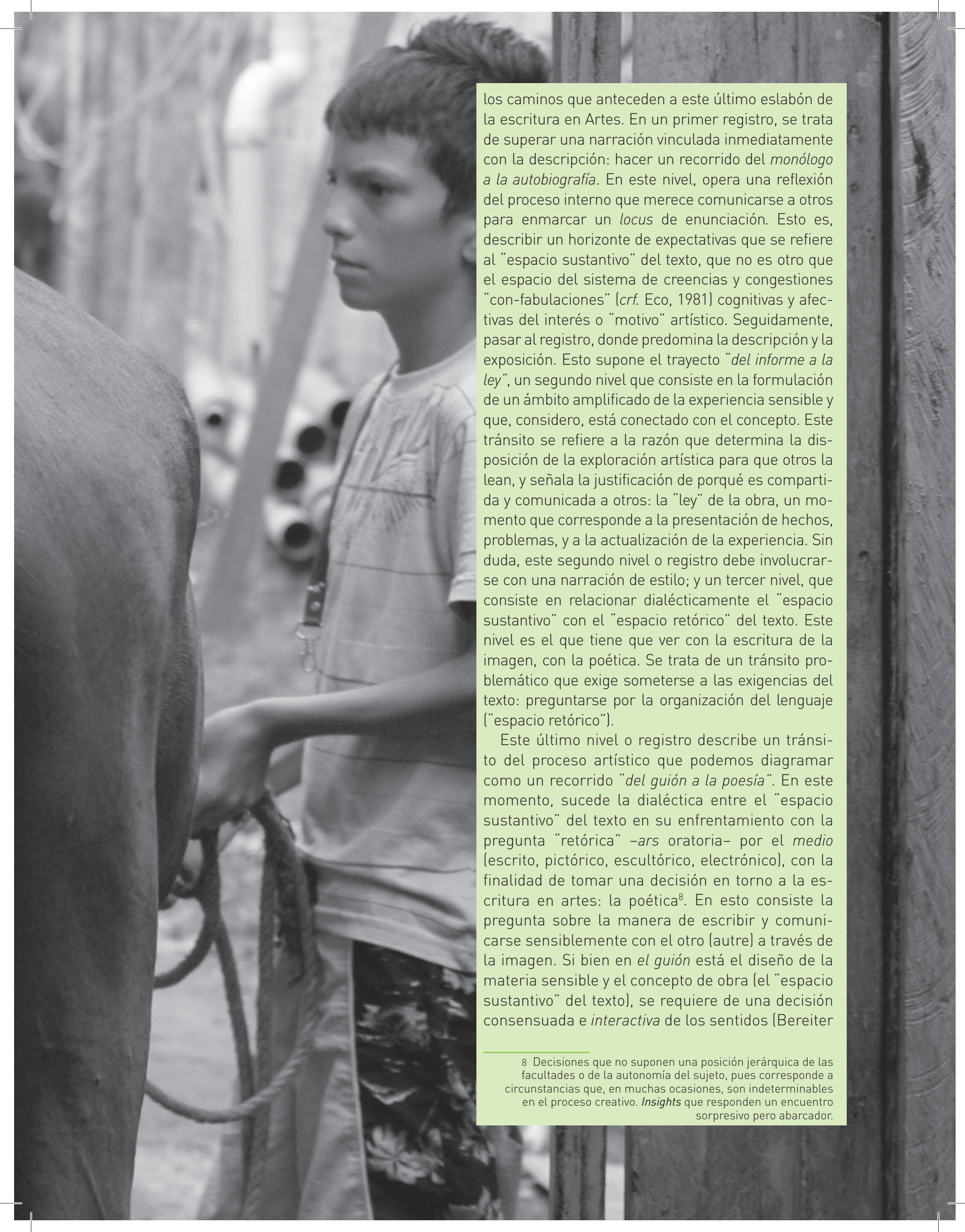


\& Scardamalia, 1987; Bustamante, 1993; Perkins, 1985), una decisión "retórica" y "expresiva" en el camino hacia la poética. Es aquí cuando el ensayo se anuncia como el resultado, o un espacio intermedial, que conjuga procesos de orden estético y epistémico que están comprometidos en la creación artística.

En suma, se nos presenta como un centauro de los géneros donde se articulan y relacionan el "espacio sustantivo" y "el espacio retórico". Es el lugar donde se escribe el texto en Artes; el espacio intermedial entre los múltiples lenguajes textuales y el lenguaje de la imagen (Gombrich \& Diedier, 1991). La construcción de un ensayo -en forma de género textual- dirige las competencias de transformar una representación conceptual y sensorial propia, en una codificación que la valore y la haga extensible. El recorrido que hemos diagramado, que se desprende del análisis del ensayo como género textual, nos ha permitido concebir una cadena escalonada de diferentes niveles de la expresión escrita para establecer correspondencia con diferentes registros de la prosa que exige el trayecto hacia la construcción de un ensayo en una equivalencia con fases del proceso artístico: la fase de descripción (del monólogo a la autobiografía), de narración (del informe a la ley, pasando por la crónica), de exposición (del guión a la poesía ), y finalmente, en la resolución de la tensión entre el "espacio sustantivo" del texto y la exigencia del "espacio retórico", se logra la escritura del ensayo: la obra.

Aunque parezca una secuencia esquemática y aparentemente lineal, en todas sus perspectivas es un proceso recursivo que busco destacarlo de esta manera para resaltar el hecho de complejidad del proceso escritural y la necesaria noción del proceso artístico como una práctica de escritura.

Me resta una última consideración que también se desprende de la reflexión del centauro de los géneros como marco de una modalidad de relación entre el artista y el texto. Se trata de entender algunas de las "texturas" y "textualidades" que habitan en nuestra contemporaneidad para asumir el reto sugerido por el profesor Gilberto Bello. Si bien él sugirió entender los códigos ligados a nuevos lenguajes como el tecnológico -lo que permite establecer El Ensayo-, en esta perspectiva, como espacio intermedial de relación entre el aparecer de las imágenes ("espacio sustantivo") y las palabras ("espacio retórico"), está la incursión en una relación que en la contemporaneidad parece unirse no solamente en el registro tecnológico: la actividad científica y la actividad artística. En la mente de muchos: "científicos y artístas pertenecen a dos especies distintas, que se dedican además a actividades radicalmente diferentes. A los primeros, por lo general se los asocia con el mundo de la verdad, la evidencia, el método riguroso: el saber. A los segundos, con el mundo de la imaginación, la inspiración, la espontaneidad: el sentir" ". Sin embargo, cuando consideramos detalladamente el concepto de escritura como una tecnología de la palabra, nos referimos a un sistema de pensamiento, a un proceso que reestructura la conciencia porque media y codifica la experiencia sensible (Cassany 1995, 2000; Eco, 1981; Perkins, 1985; Ong, 1987; Bereiter \& Scardamalia, 1987). En este sentido se hace imposible disociar las facultades sensibles de las cognitivas y separar ambos universos, como lo indica el reciente artículo del periódico El Tiempo tras la pregunta "Ciencia y arte: ¿caminos entrecruzados? La escritura de un ensayo lsi se considera explícitamente como género textual y no solamente como metáfora del proceso de investigación-creaciónl demuestra que la dimensión epistémica es equivalente (en dimensión) a la estética, en tanto funcionan como actividades de procesos psicológicos superiores Vigotsky, 1995; Perkins, 1985). Arte y Ciencia participan de operaciones similares en el proceso, pues exigen la misma relación significativa entre el "espacio sustantivo" y el "espacio retórico" con el texto para obtener resultados de creación lpoética de la imagen en el caso de las artes) y de argumentación (para el caso de la ciencia). Ambos son campos problemáticos de escritura y exigen el mismo rigor en la elaboración, la planeación, la experimentacion y composición. Tal como lo ha presentado recientemente Stephen Wilson en los reportajes que le ha hecho la BBC de Londres y en su libro Arte + Ciencia hoy: "Tanto científicos como artistas necesitan recurrir a la imaginación. El trabajo de ambos puede describirse como la exploración de una realidad que no conocen completamente. Y a lo que ambos aspiran es a ofrecer algún tipo de explicación y valoración sobre el mundo" en la fórmula de "transformar el conocimiento". Esto es equivalente a escribir productivamente.

9 La consideración procede del artículo "Ciencia y arte: ¿caminos entrecruzados? La obra de un número creciente de artistas está más cerca de los laboratorios que de los museos. ¿Es ese el arte del siglo XXI?" publicado en el periódico colombiano El Tiempo, el miércoles 10 de noviembre de 2010. 


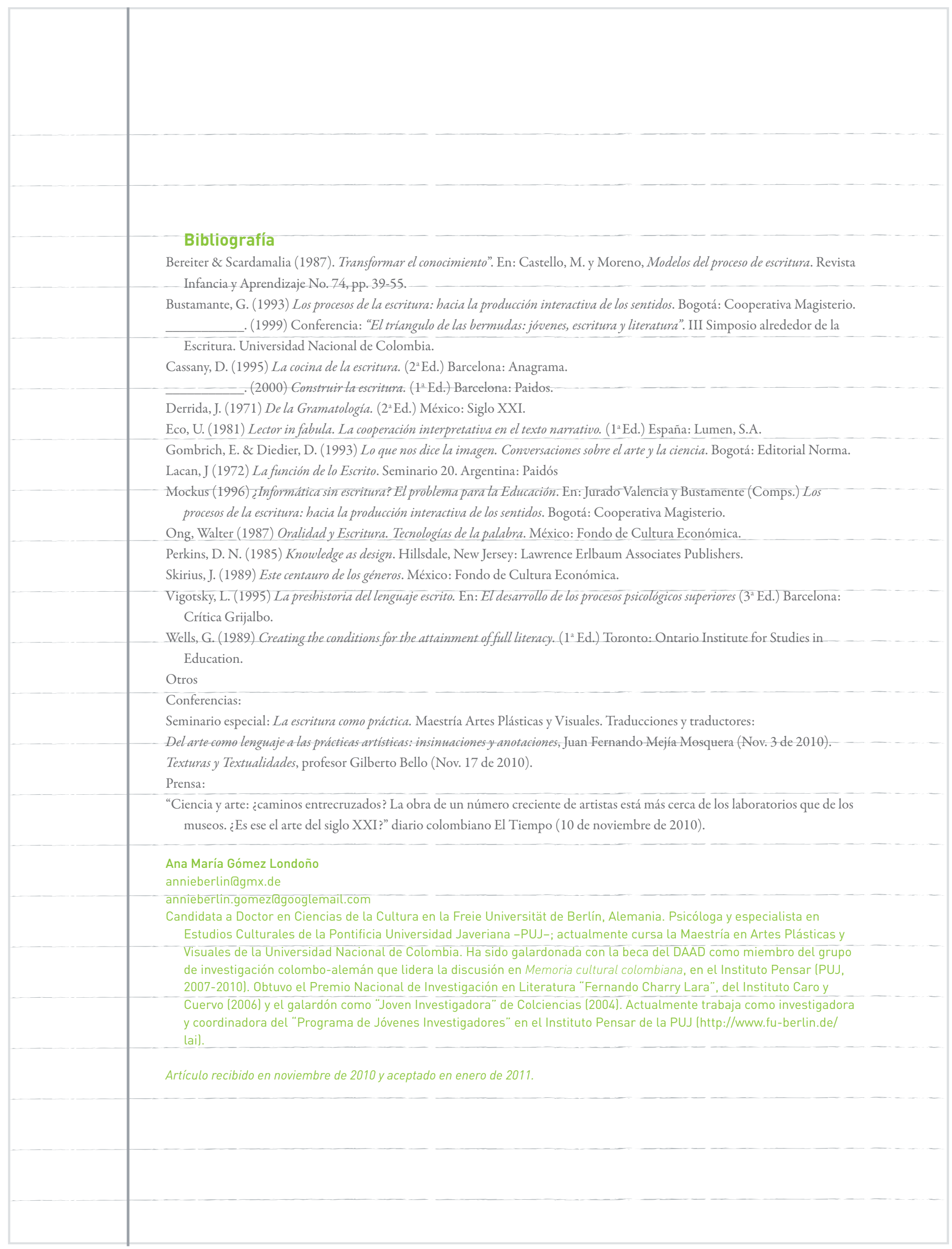

